Editorial:

\title{
Emotional labour and solving social work problems
}

by

Associate Professor Ingunn Studsrød, PhD

University of Stavanger, Stavanger, Norway 
Keywords supplied to the papers in this issue of Journal of Comparative Social Work are argumentation, critical reflection, professional boundary, democratic professionalism, etc. For me, all of these words connote intellectual and rational social work activities or practices. Thus, intellectual thinking and rationalization seem highly pertinent to social work research, as well as professional learning and practices around the world.

Nevertheless, when reading through the papers in this issue, I also observed several passages connoting quite different issues, e.g. in the following: "I am a passionate, sensitive, emotional social worker..." (in Liza Manolis' contribution), “Amina's words rendered me powerless and I was afraid of the consequences..." (in Vyda Mamley Hervie's essay), "Important social work concepts such as ...empowerment, diversity, self-respect..." ( in Rolv Lyngstad's article) and "...both of the authors experienced a feeling of loss owing to their attachment to the participants" (in Susanna Rautio's and Kati Hämäläinen's contribution). Passionate, sensitive, emotional, powerlessness, fear, empowered, self-respect, feeling of loss, etc. are all labels signifying feelings or emotions among social workers, social work researchers or social work users. Hence, these articles, although some more implicitly, also cover a different matter of the characteristics of social work, i.e. what could be called emotional work or emotional labour (Hochschild, 2003).

The term emotional labour was first introduced by the American sociologist Arlie Russell Hochschild $(1975,1979,2003)$. Her research was in the airline industry, and focused particularly on the emotional work of flight attendants. According to Hochschild (2003), emotional labour is the amount of effort involved in work that entails face-to-face contact with the public, which is exercised by several professions such as social workers, hairdressers, police officers and nurses. Additionally, the worker who does emotional labour is required to produce an emotional state in another person, such as for instance self-respect, feelings of security, hope or pride in social work users. Emotional labour has to do with dealing with one's emotions, and could be described as "feeling management" performed as paid work (Gorman, 2000). In the sociology of emotions, a fundamental concern is to understand how emotions are regulated by cultures and social structures (Wharton, 2009). Emotional 
labour takes place in context, e.g. in workplaces or occupational sites. In our context, emotional labour has to do with social workers managing their feelings according to the "feelings rules" of social work organizations or social work research. Feeling rules represent what type of emotions a person should express, as well as the degree of that expression according to the person's societal role (Hochschild, 2003). Since the feeling rules may vary according to different occupational sites, hospice social workers may be expected to display other emotions, or emotional degrees, than those working with looked-after children or doing social work research, even when faced with equal stimuli or situations (Leeson, 2010). Following the theory, a social work job demand is to express appropriate emotions during face-to-face or voice-tovoice interaction, in addition to sensing the emotion of the interaction partner. In doing emotional labour, social workers suppress emotions deemed undesirable, as well as introducing emotions that are expected or demanded. Such emotional regulations are achieved through surface acting, i.e. pretending to feel what is expected. Furthermore, emotional regulations could also be achieved by deep acting, which requires the social worker to draw upon his/her own personal reserves in order to bring forth the required facial or bodily display of emotions. Emotion work as part of the job implies the display of desired emotions, even in unpleasant situations. For example, despite their private feelings of anger, sorrow, fear or disappointment, social workers may be expected to express feelings of joy and relaxation.

Emotional labour often has personal costs. Hochschild (1983) maintained that in the long run, showing emotions not felt at that moment would lead to the alienation of one's feelings, which could cause ill psychological health (Zapf \& Holtz, 2007). Thus, the personal costs can be high. Leeson (2010) has reviewed reseach literature and revealed that personal costs can be especially high when the "feeling rules" are at odds with personal values and beliefs. The personal costs can also be heavy if there is little or no support or recognition in the organization of the work being done or in the energy used by the social worker. Personal costs may include disengagement in work and burnout, which could also mean that a social work practioner is unable to fully and effectively participate in the emotional engagement required to work successfully with their clients. That being said, it should also be noted that emotional labour also offers the rewards of creativity, identity and energy by social workers 
(Leeson, 2010, p. 484). All in all, the theory of emotional labour fills the gaps in the literature that seem to comment on a society filled with social workers with no heart or soul (Theodosius, 2008). In that respect, the editors are highly grateful for how the contributors in this issue cause us to explore and reflect on the width of the requirements, contexts, competencies and costs for social workers in solving social work problems. Enjoy the reading.

In the first article in this edition, Kati Hämäläinen and Susanna Rautio consider the meaning of the participants' home as an interview context when studying sensitive family issues. The article is based on two qualitative family studies by the authors on foster children's perspectives on their home and family relations and client families' experiences of preventive family support. Both studies address sensitive family issues, in particular Finnish child welfare. The main research findings concern different aspects that the authors found in the course of their home interview studies: differences between home and university, as well as the possibilities and challenges of home and comparisons of adults and children as focus groups.

The second article, which is by Kati Valpalahiti, Miika Marttunen and Leena Laurinen, is about a teaching experiment in which social work students practiced problem solving through argumentative tasks. The authors reports a quasi-experimental study investigating whether role-play simulation conducted both online and face-to-face improved students' problem solving on societal issues. The main research results revealed that role-play simulations as a part of long lasting development processes of argumentative problem solving seem to be beneficial for social work students' professional development.

The point of departure in Rolv Lyngstad's article is on contemporary changes in the relationship between national and local decision making within the Norwegian political system. Lyngstad shows that the last decades' centralization tendencies seem to be challenged by a "new" emphasis on local discretion. The article discusses how this will affect social work in municipalities, and argues that professional social work must be context-specific, meaning that local knowledge in a wide sense is a prerequisite for good social work. 
In Liza Manolis' essay, entitled "Memories from the frontline: One unforgettable experience of a child protection social worker in northern Canada", a critical incident involving an experienced child protection social worker and a first nation family is deconstructed utilizing Jan Fook's Critical Reflection Technique (2002). This deconstruction process investigates the issues of professional boundaries, revictimization, vicarious trauma, power and oppression and the ideas surrounding what a "real" and "good" social worker is. Through the reconstruction process, it is discovered that the assumptions underlying these issues are not helpful, and in fact are harmful to both the social worker's sense of self, as well as to social work practice.

Vyda Mamley Hervie looks back at her practice encounter with witchcraft, HIVIAIDS and disability in Ghana. Social work students are trained to develop and maintain a professional sense of integrity, particularly when working in environments beyond their control. In this essay, she is using critical reflection to look back at her personal practice encounter with witchcraft, HIVIAIDS and disability. In doing this, she explores "taken for granted" ways of thinking and doing things into best practices, and through a process of deconstruction, key themes of professional boundaries and social justice are explored.

\section{References:}

- Gorman, H. (2000). Winning hearts and minds? - Emotional labour and learning for care management work. Journal of social work practice, 14(2), 149-159.

- Hochschild, A. R. (1975). 'The sociology of feeling and emotion: Selected possibilities.In M. Millman, \& R. Kanter (Eds.), Another Voice, Garden City, NY: Anchor.

- Hochschild, A. R. (1979). 'Emotion work, feeling rules and social structure'. American Journal of Sociology, 85, 551-575.

- Hochschild, A. R. (2003). The managed heart: Commercialization of human feeling. Berkeley, Los Angeles, London: University of California Press.

- Leeson, C. (2010). The emotional labour of caring about looked-after children. Child and family social work, 15 (4), 483-491.

- Theodosius, C. (2008). Emotional labour in health care. The unmanaged heart of nursing. London and New York: Routledge.

- Wharton, K. (2009). The sociology of emotional labor. Annual review of sociology, 35(2), 147-165.

- Zapf, D., \& Holtz, M. (2007). On the positive and negative effects of emotion work in organizations. European journal of work and organizational psychology 14 (1), 1-28 